\title{
A machine learning approach to find the determinants of Peruvian cocaine local price
}

\section{Yulisa Margoth Huamán Ivala ${ }^{a^{*}}$, Alexander Flores Guillen ${ }^{a}$, Elizabeth Yadhira Perez Evangelista ${ }^{a}$, Ruben Ángel Ruiz Parejas ${ }^{b}$ and Jimmy Alberth Deza Quispe ${ }^{c}$}

${ }^{a}$ Graduate student, Computer and Systems Engineering Program, Faculty of Engineering, Universidad Continental, Huancayo-Junin, Peru ${ }^{b}$ Full-Time Professor, Computer and Systems Engineering Program, Faculty of Engineering, Universidad Continental, Huancayo-Junin, Peru 'Assistant Researcher, Universidad Continental, Huancayo-Perú, Peru

\section{H R O N I C L E}

Article history:

Received: June 20, 2021

Received in revised format: September 20, 2021

Accepted: November 20, 2021

Available online: November 20, 2021

Keywords:

Coca illegal crops

Lasso

$V A R$

OLS

\section{A B S T R A C T}

The coca leaf has many uses in the Peruvian culture. Although there are legal usages, people employ coca for illicit business. The most infamous illegal use is cocaine production. The cocaine business is highly profitable, but it harms human health. Then, what are the determinants of cocaine price? The current analysis aims to get the variables with the capability to explain the cocaine prices in Peru. The period analyzed is 2003-2019. The study gathered variables from DEVIDA and UNDOC databases. The Lasso technique selected the variables with the best capability to predict cocaine price. Those variables were: ENACO acquisition, coca seizures, and coca crops. OLS, VAR, and Granger analyses employed those variables to analyze the relationship between them. According to the OLS analysis, both ENACO acquisition and coca crops had adverse effects on cocaine prices, while coca seizures were positively related to the cocaine price. VAR analysis showed that only ENACO acquisition had a short-term relationship with the dependent variable. Moreover, it showed that the whole set of variables influenced the dependent variable. The Granger analysis proved that there was a cause-effect relationship between ENACO acquisition and cocaine price. Hence, the ENACO purchases expansion can rest the attractiveness of illegal groups to farmers. However, lowering cocaine prices might attract more users. Therefore, educational activities are also required.

\section{Introduction}

Coca leaf is a controversial issue for both Peruvians and foreigners (Thoumi, 2005). On one side, Andean people consume coca to obtain energy for hard labor (Fernandez, 2017). Moreover, it has medicinal properties employed in actual medical supplies and is under research for new usages (Biondich \& Joslin, 2016). Furthermore, people in Latin American countries consider coca leaf as divine (Conzelman \& White, 2016). However, cocaine production comes from the coca leaf (Pacini \& Franquemont, 1986). In 1860 cocaine was regarded as a marvelous alkaloid (Gootenberg, 2001). This reputation made the United States and Western Europe the main destinies of cocaine (Gootenberg, 2001). It is crucial to add that the first-ever crystallized cocaine came from the Peruvian coca leaf (Gootenberg, 2001).

In those years, a wide range of ailments employed cocaine for therapeutic reasons (dos Reis Jr, 2009) Furthermore, its stimulant effects replaced coffee or tea (Gootenberg, 2001). Maybe, the most famous employment of cocaine was in the first versions of the widely known "Coca-Cola" beverage (Piazza, 2015). In surgery, cocaine was a kind of anesthesia for complex surgery as well as for psychiatry (Seelig, 1941). In fact, in those years cocaine was legal.

* Corresponding author.

E-mail address: 76175352@ continental.edu.pe (Y. M. H. Ivala)

(C) 2022 by the authors; licensee Growing Science, Canada. doi: $10.5267 /$ j.ijdns.2021.11.009 
In the last decade of the nineteenth century, scientists discovered recreational uses for cocaine (Gootenberg, 2001). Hence, the cocaine market became profitable for the poor Peruvian economy (Gootenberg, 2001). However, in the first half of the twenty centuries, cocaine declined in both prestige and use. In the first year of that century, anti-cocaine movements included cocaine in the Jones-Miller act that banned all cocaine imports in the United States (Spillane, 1994). Nonetheless, Europeans were still interested in the coca leaf boundaries.

However, it changed in the second part of the twenty centuries since international agreements aimed to eradicate cocaine and coca production (Thoumi, 2005). Nixon's war declaration in the 1970s conceived the Drug Enforcement Administration (Daniels, 2006). The DEA intends to control drugs all over the world. In Peru, the Programa de Erradicación del Proyecto Especial de Control y Reducción de Cultivos Ilegales en el Alto Huallaga or CORAH was created in the second half of the 20th century (Rojas \& Parra, 2018). In the 21st century, the Comisión Nacional para el Desarrollo y Vida sin Drogas, DEVIDA, was created to fight against drugs (DEVIDA, 2017).

The Peruvian strategy in the drug war considers the buying of crops for legal uses through ENACO (Durand, 2005). However, illegal activities are more profitable for farmers than legal ones (Thompson \& Uggen, 2012). Cocaine is highly valuable and increases its value in rich countries (Fryer et al., 2013). Hence, it makes cocaine traffic one of the most profitable businesses in the world (McDermott et al., 2021). As stated before, the Peruvian coca leaf is the ingredient to produce the highest quality cocaine. On average, the paste and cocaine hydrochloride cost in the USA, Europe, and Asia at US\$ 1000 per kilo (DEVIDA, 2020). That price reaches more than 57 times its original price (McDermott et al., 2021). As with all criminal activities, the cocaine trade causes violence (National Institute on Drug Abuse, 2016). Also, it destroys the lives of addicts around the world. Then, it is possible that lowering the price can move farmers to plant other crops. Hence, what can be the determinant of cocaine price? Moreover, it would be interesting to question whether it is more convenient that prices remain high or not. The current analysis will answer those queries.

\section{Literature Review}

\subsection{Previous Studies}

In academic literature, few previous studies have examined the determinants of cocaine price. For instance, Thompson and Uggen (2012) studied the connection between cocaine price and the Colombian peso. They employed quarterly cocaine prices from 1982 to 2007 published by the Office of National Drug Control Policy. The research harnessed Vector error correction and forecast error variance decomposition to study that relationship. They found that the cocaine prices affected the value of the Colombian peso. Freeborn (2003) found that consumers evaluate both quality and weight when maximizing profit. Both consumers and dealers value the risk of legal penalties, which affect the price. DiNardo (1993) studied the connection between law enforcement and cocaine prices. However, they did not find any relationship between DEA seizures and cocaine prices. Furthermore, Desimone and Farrelly (2001) investigated cocaine price through the respondents of the 1990 to 1997 National Household Surveys on Drug Abuse. They found that cocaine prices are inversely related to cocaine and marijuana adult demand. Nonetheless, there was no association between cocaine price and juvenile drug demand and the marijuana price effect. Also, they found that arrest diminishes both types of drug employment. Additionally, Félix \& Portugal (2017) studied the relationship between the drug decriminalization policy and opiates and cocaine price. The study found that both drug prices did not increase due to softer drug law enforcement. Sumnall et al. (2004) scrutinized alcohol, amphetamine, cocaine, and ecstasy prices. Focusing on cocaine price, they found that it was a complementary drug, and its demand was elastic. Hence, when the cocaine price fell, its demand increased.

\subsection{Variables definition}

\subsubsection{Cocaine price}

Cocaine is the most infamous coca leaf product. In the nineteenth century, French wines employed cocaine to enhance the flavor (Grinspoon \& Bakalar, 1981). Later, health professionals like Sigmund Freud managed cocaine to treat patients (Seelig, 1941). Moreover, physicians provided anesthesia that contained cocaine. Since it was a free-to-use drug, reports of intoxication increased along with deaths (Gootenberg, 2001). Also, addiction issues began among cocaine users. Nowadays, cocaine is legal only under strict conditions, especially in health practice (Wesson \& Smith, 1977). However, this does not avoid people seeking and paying high quantities of money to get cocaine. Thus, reports about overdosing and deaths have been rising among cocaine users (Díaz et al., 1995). Also, diseases are transmitted by sharing needles and snorting to get high through cocaine consumption (Arif, 1987). Furthermore, it carries financial, psychological, familiar, and other undesirable effects (Daley, 2013).

Cocaine price, like any other scarce product, relies upon offer and demand. Hence, if there are consumers, there will be suppliers. Coca supplier countries like Peru, Colombia, and Bolivia, the cocaine price is low compared to rich countries. According to Zhu et al. (2014), cocaine price relies on the purity grade, too. 


\subsubsection{ENACO coca acquisitions}

ENACO is a state-owned firm that acquires coca leaf to the producers for legal uses (Trigoso, 2017). Nonetheless, the main disadvantage of this practice is the price gap between ENACO and drug dealers (Glave \& Rosemberg, 2005). Moreover, ENACO cannot buy the whole coca offer available. Unfortunately, the coca offer is many times traded in remote towns without any control. Due to the antiquity of coca production, coca leaf is a way of life for many farmers, and even it is their wealth resource (Castillo, 2012).

\subsubsection{Coca crops}

The coca crop continues to increase because of its profitability and adaptation to the forest (Devida, 2020). Since coca crops are popular among farmers, it is not simple to track their exact quantity. In consequence, many crops go to elaborate illicit drugs. Therefore, one measure taken by both the Peruvian government and international agencies is to eradicate the coca crops by directly destroying them (DEVIDA, 2017).

\subsubsection{Coca leaf confiscation}

Much of the coca harvest goes to illegal drug production like chlorhydrate of cocaine or cocaine paste. Hence, the Peruvian police, by raids and road controls, confiscate coca leaves that do not have evidence of legal purposes (Esquivel et al., 2019).

\section{Materials and Methods}

\subsection{Theoretical approach}

\subsubsection{Ordinary least square}

An Ordinary Least Square regression is commonly expressed as:

$$
y=\beta_{0}+\beta_{1} x_{1}+\cdots+\beta_{k} x_{k}+u
$$

where, $y, x_{1}, \ldots x_{k}$ are the analyzed variables, $u$ is the error, and $\beta_{0}+\beta_{1}+\beta_{2} \ldots \beta_{k}$ is the coefficient (Wooldridge, 2010). An OLS model should have some conditions to be considered valid. One condition is the linear relationship between the independent and the dependent variables (Burton, 2020). The F-test is useful to verify the linearity of an OLS regression. Further, the studied variable's error terms cannot be correlated (Burton, 2020). Here, the Durbin-Watson test checks that condition. Fonti (2017) considers the normal distribution condition necessary for parametric analysis. Wooldridge (2010) also states that normal distribution enables maximum efficiency in OLS results. The other assumption that ensures OLS estimator efficiency is homoscedasticity. Homoscedasticity asks for the variance to be constant and avoids standard error miscalculations (Yang et al., 2019). Finally, the non-multicollinearity assumption avoids redundancy among independent variables. Hence, it makes the OLS results well-built and accurate (Burton, 2020). The Variance Inflation Factor test is proper to check multicollinearity.

\subsubsection{LASSO}

Lasso means Least Absolute Shrinkage and Selection Operators. Lasso, a machine-learning approach, seeks the optimal quantity of independent variables (Fonti, 2017). Benvenuto et al. (2018) state that Lasso is a supervised machine learning approach. Lasso combines both wrapping and filtering methods, as suggested by Fonti (2017). Hence, Lasso classifies and erases selected coefficients to zero (Tibshirani, 1996). Henceforth, Lasso finds an equilibrium between variance and bias. That equilibrium enables us to make an optimal regression model without redundancy (Fonti, 2017). Lasso can be expressed as:

$$
\operatorname{Min}=\left[\left(\|Y-X \beta\|_{2}^{2}\right) / n\right] \text { subject to } \sum_{j=1}^{k}\|\beta\|_{1}<t
$$

where $\mathrm{t}>=0$, reflects the upper limit of the coefficients sum. Also Eq. (2) can be expressed as:

$$
\hat{\beta}(\lambda)=\operatorname{argmin}_{\beta}\left(\frac{\|Y-X \beta\|_{2}^{2}}{n}+\lambda\|\beta\|_{1}\right)
$$

where the expression $\left|Y-X \beta \|_{2}^{2}\right|$ is like $\sum_{i=0}^{n}\left(Y_{i}-(X \beta)_{i}\right)^{2}$; and $\|\beta\|_{1}$ is $\sum_{j=1}^{k}\left|\beta_{j}\right|$ y $\lambda>=0$. The $\lambda$-lambda- estimator controls the penalty force. Therefore, the longer $\lambda$ is, the longer the penalty. $\lambda$ and $t$ have a negative relationship. Fonti (2017) claims, in consequence, that when $t$ goes to infinity, $\lambda$ becomes 0 . As stated before, when the value of the coefficient is zero, it is erased. Lasso only keeps independent variables with non-zero values.

For the current study, the $\lambda$ selection will be two Cross Validation and Adaptative. Lasso Cross-Validation or CV splits the sample into two. They are called training and testing sub-samples (Reitermanová, 2010). The reason behind this is to ensure a consistent estimation of the model's performance. The CV splits the sample into ten folds. When the technique chooses one- 
fold, a linear regression utilizes the non-selected folds (Stata, 2019). After that, regression coefficients estimate the selected fold. Next, the technique calculates the coefficients for the other folds. At the end of the analysis, ten average squared errors or MSE are measured (Stata, 2019). The CV function stops with the minimum value of $\lambda$. After that, the model chooses the $\lambda$ with the highest prediction power and the littlest MSE.

The Lasso adaptive or AV employs the CV approach to select $\lambda$ in higher frequencies. In consequence, the model performs multiple functions at the same time. Again, the model erases coefficients with zero values. However, the weak non-zero coefficients get penalty weights to make them become zero in the next prediction. Consequently, only strong coefficients have a chance to get chosen. Like CV, $\lambda$ with the highest prediction power and the minimum error is selected (Stata, 2019).

\subsubsection{Vector Autoregressive Model}

This technique can analyze the relationship between a set of variables. It emerges as a combination of many autoregressive models that build a vector between the examined variables (Hossain \& Kamruzzaman, 2015). Papanicolas \& McGuirev (2011)suggest employing this model in data with time series. Furthermore, Lütkepohl (2007) claims that this technique makes segregation between the dependent and independent variables. It can be expressed as:

$$
y=\Gamma_{1} X_{t-1}+\varepsilon_{t}
$$

Also:

$$
\begin{aligned}
& y_{t}=\mathrm{c}+\varphi(\mathrm{B}) \mathrm{y}_{t}+\varepsilon_{t} \\
& y_{t}=\mathrm{c}+\left(\varphi_{1} \mathrm{~B}+\varphi_{1} \mathrm{~B}^{2}+\cdots+\varphi_{p} \mathrm{~B}^{p}\right) \mathrm{y}_{t}+\varepsilon_{t} \\
& \varepsilon_{t} \sim N(0, \Sigma)
\end{aligned}
$$

Here, it is also necessary to evaluate some necessary assumptions as suggested by Stock \& Watson (2001). Those assumptions are stationarity of data at first difference, normal distribution, and independence among variables. The unit root examination is valuable for examining the stationary premise. For the second assumption, the current analysis harnessed the Jarque Bera test. Finally, the Lagrange test is helpful to assess the autocorrelation assumption.

\subsubsection{Granger Causality Test}

The Granger causality test is valuable to investigate cause and effect connections between variables in VAR (Uteulievna et al., 2016). The Granger test is expressed as:

$$
\begin{aligned}
& V_{s, t}=\alpha_{1}+\sum \beta_{i} V_{s, t-1}+\sum \rho_{i} V_{M, t-1}+\varepsilon_{t} \\
& V_{M, t}=\alpha_{2}+\sum \theta_{i} V_{s, t-1}+\sum \kappa_{i} V_{M, t-1}+\varepsilon_{2 t}
\end{aligned}
$$

Uteulievna et al. (2016) state that it is possible to get causality of $V_{M}$ to $V_{S}, V_{S}$ to $V_{M}$, bidirectional causality, and no causality. The current study aimed to find the determinants of Peruvian cocaine price. Hence, the study collected an initial set of variables. Both DEVIDA and the United Nations Office on Drugs and Crime were the sources of the variables. The variables were: coca illegal crops, confiscated coca leaves, eradicated coca crops, seized cocaine, confiscated cocaine paste, coca leaf price, coca leaves acquired by ENACO, cocaine price in Europe, and cocaine price in the United States. Lasso provided the best predictors. Next, OLS, VAR, and Granger analyzed the set of variables. It was necessary to check the assumptions of OLS estimation. Before calculating VAR and Granger, the analysis needed to estimate the lag number. Also, it was essential to verify the presence of long-term relationships using the Johansen test. Next, the Granger test was employed to establish the cause-effect relationships. Both Excel and Stata have been employed to perform the statistical analysis.

\section{Results}

Table 1 shows the descriptive statistics of the variables employed. In 2014 and 2019, the cocaine price reached its maximum value. The ENACO coca acquisition had its lowest value in 2018. In that year, ENACO only bought one ton. Coca crops had their peak in 2011 and their lowest value in 2015. However, coca confiscation had its peak in the last year of the period analyzed. Figure depicts that cocaine prices in Peru continuously increase over time. Moreover, Figure 2 shows that the coca leaf quantity acquired by ENACO has been decreasing since 2007. Figure 3 reveals that the coca crops have been increasing since 2015. Also, in 2015, the Peruvian authorities seized the maximum tons of coca leaf confiscated, as shown in Fig. 4. 
Table 1

Descriptive Statistics

\begin{tabular}{|c|c|c|c|c|}
\hline \multirow{2}{*}{ Measures } & \multicolumn{3}{|c|}{ Variables } & \multirow[b]{2}{*}{ Confiscation leaf } \\
\hline & Price in Peru * & ENACO & Crops & \\
\hline Mean & 1166.67 & 2273.46 & 51969.94 & 13797.59 \\
\hline Median & 1021.00 & 2212.00 & 51400.00 & 13332.00 \\
\hline $\operatorname{Max}$ & 1718.00 & 3109.00 & 62500.00 & 25050.00 \\
\hline Min & 823.00 & 1357.21 & 40300.00 & 3574.00 \\
\hline \multirow[t]{2}{*}{ Standard deviation } & 321.78 & 572.53 & 6764.97 & 5577.07 \\
\hline & $*$ in US\$ & ** kilograms & $* * *$ in hectares & ** kilograms \\
\hline
\end{tabular}

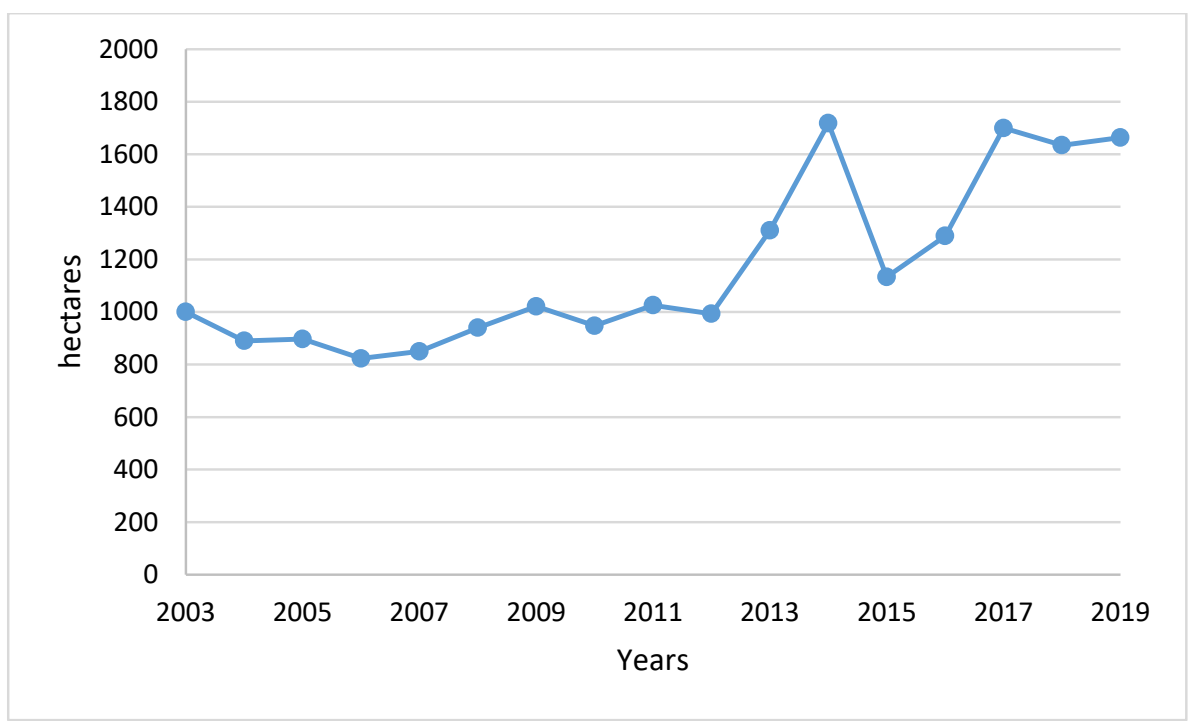

Fig. 1. Cocaine price in Peru

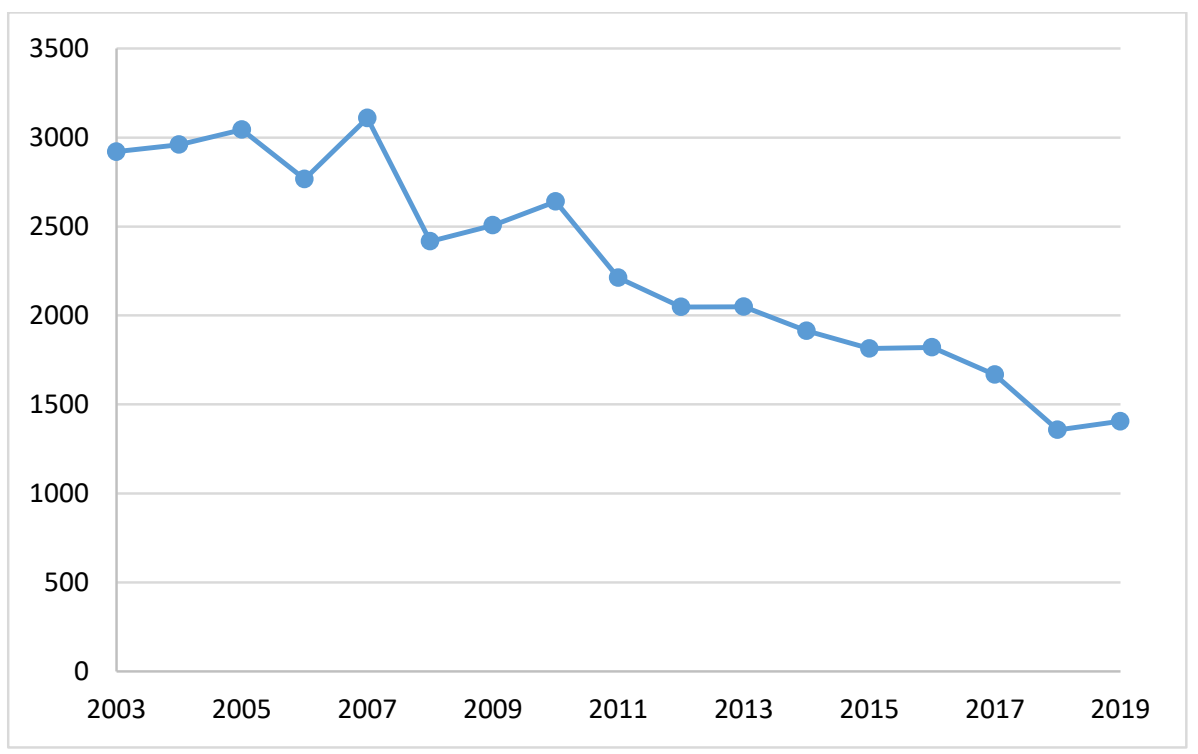

Fig. 2. Acquired quantity by ENACO 


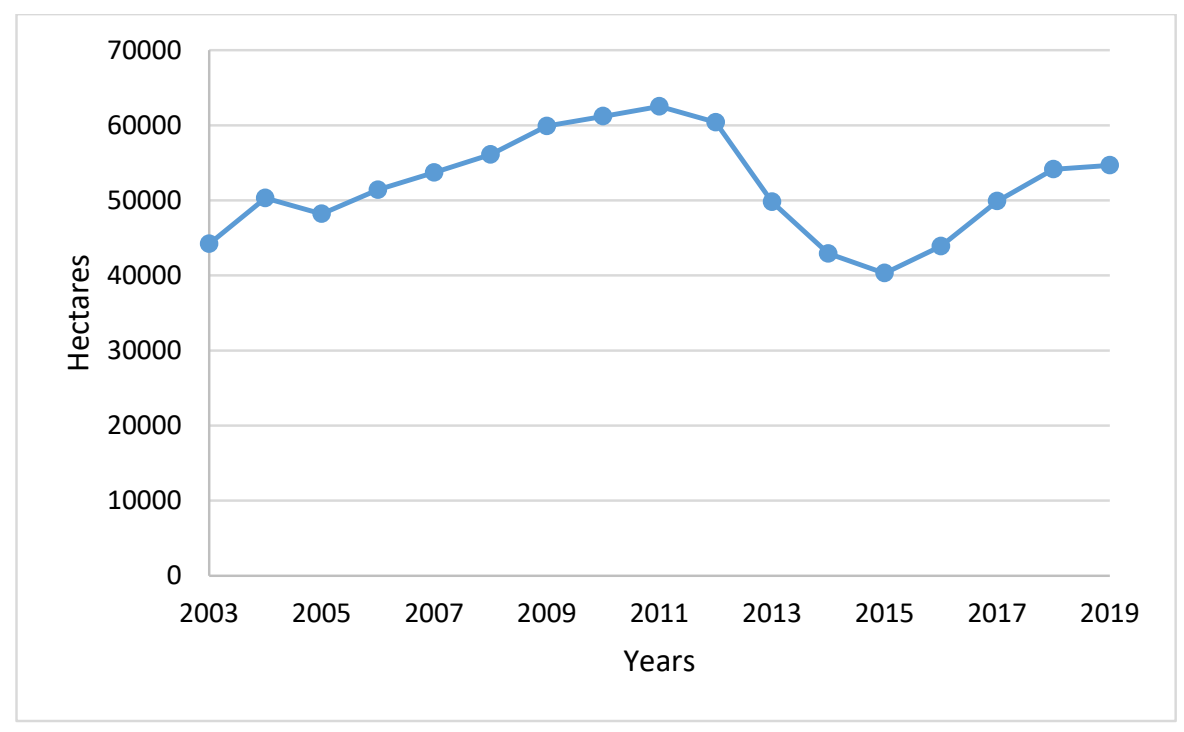

Fig. 3. Coca leaf crops

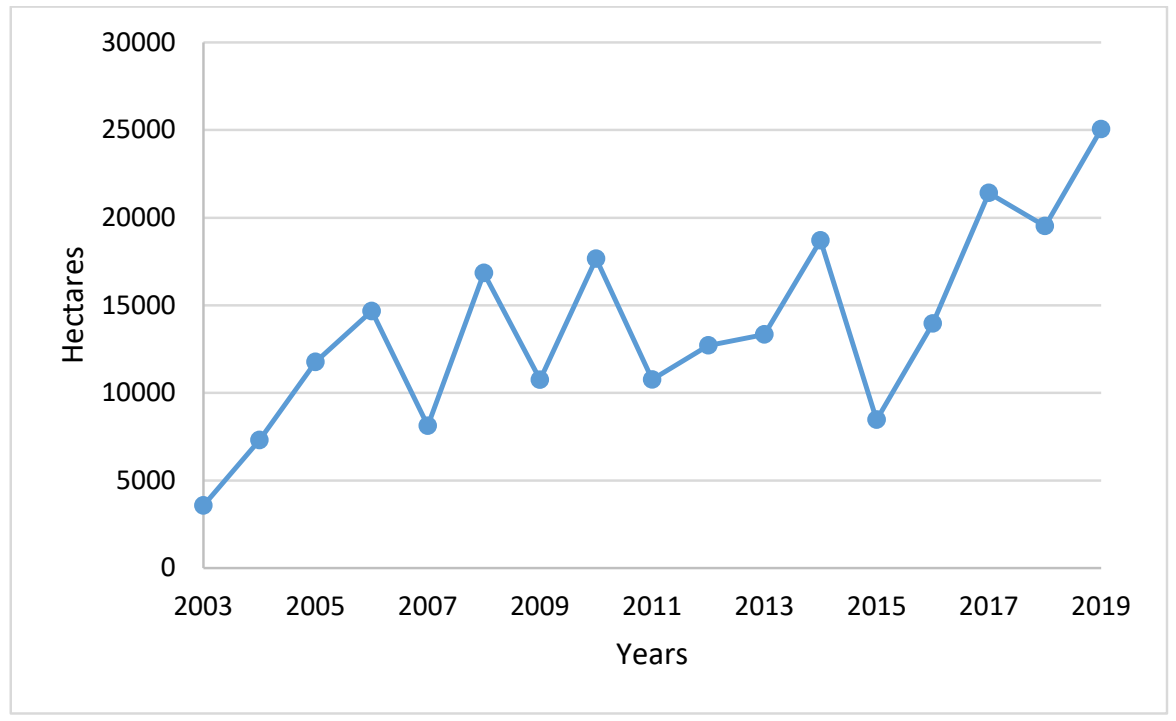

Fig. 4. Confiscation leaf

Table 2

\begin{tabular}{|c|c|c|c|c|c|}
\hline LASSO technique & ID & Lambda & Number of non-zero coefficients & Out of sample R2 & Cross validation mean prediction error \\
\hline \multirow{5}{*}{ Cross Validation } & 1 & 263.91 & 0 & 0.0731 & 104574.10 \\
\hline & 11 & 104.09 & 3 & 0.4564 & 52977.30 \\
\hline & $* 12$ & 94.84 & 3 & 0.4591 & 52710.53 \\
\hline & 13 & 86.42 & 3 & 0.4576 & 52860.32 \\
\hline & 15 & 71.75 & 3 & 0.4429 & 54287.34 \\
\hline \multirow{5}{*}{ Adaptative } & 18 & 571.36 & 0 & 0.191 & 116058.00 \\
\hline & 37 & 97.55 & 1 & 0.5977 & 39206.95 \\
\hline & *38 & 88.89 & 1 & 0.6019 & 38796.25 \\
\hline & 39 & 80.99 & 1 & 0.5999 & 38992.27 \\
\hline & 88 & 0.85 & 3 & 0.4944 & 49269.37 \\
\hline
\end{tabular}

Table 2 depicts the Lasso estimation where the CV selected the id number twelve. Furthermore, in the adaptive method, the chosen id was 38. Obviously, both had the highest out-of-sample R2, the predictor, and the lowest mean prediction error. 
Table 3

Lasso post-estimation

\begin{tabular}{lll}
\hline Lambda technique selection & Mean Squared Error & R2 \\
\hline *Cross-validation & 19879.42 & 0.796 \\
Adaptive lasso & 27802.58 & 0.7147 \\
\hline
\end{tabular}

Table 4

Selected variables

\begin{tabular}{lll}
\hline Variables & Cross-validation & Adaptive lasso \\
\hline ENACO acquisition & $\sqrt{ }$ & $\sqrt{ }$ \\
Crops & $\sqrt{ }$ & \\
Coca leaf confiscation & $\sqrt{ }$ & $\sqrt{ }$ \\
Constant & $\sqrt{ }$ & \\
\hline
\end{tabular}

Table 3 reveals that the current analysis selected the cross-validation method. The CV had higher prediction power and lower MSE than the adaptive method. Hence ENACO acquisition, crops and coca leaf confiscation were selected as the best variables to predict the dependent variable, as the Table 4 shows.

Table 5

OLS Regression

\begin{tabular}{llllll}
\hline Variables & Coefficient & Standard Error & t & p $>$ t & 95\% confidence interval \\
\hline ENACO acquisition & -0.32 & 0.09 & -3.46 & 0.00 & -0.52 \\
Coca confiscation & 0.02 & 0.01 & 2.29 & 0.04 & 0.00 \\
Crops & -0.01 & 0.01 & -2.38 & 0.03 & -0.03 \\
Constant & 2312.33 & 361.49 & 6.40 & 0.00 & 1531.38 \\
F & 20.45 & & & 0.00 & \\
R2 & 0.83 & & & & \\
\hline
\end{tabular}

Table 5 shows the OLS regression. In such table, all the variables had significant relationships with the dependent variable. Both ENACO acquisition and coca crops had negative relationships with cocaine price in Peru. Only coca confiscation was positively related to the dependent variable. The F-test is significant, which gives a signal that the model is accurate. Moreover, the R2 is relatively high. Then, according to it, the chosen variables explain about $83 \%$ of effects of the dependent variable.

Table 6

OLS Assumption tests

\begin{tabular}{|c|c|c|c|}
\hline \multicolumn{4}{|c|}{ Autocorrelation test } \\
\hline chi2 & $\mathrm{df}$ & $\mathrm{p}>$ chi2 & \\
\hline 1.231 & 1 & 0.267 & \\
\hline \multicolumn{4}{|l|}{ Distribution test } \\
\hline Skewness & Kurtosis & chi2 & $\mathrm{p}>$ chi2 \\
\hline 0.44 & 0.24 & 2.22 & 0.33 \\
\hline \multicolumn{4}{|c|}{ Homoscedasticity test } \\
\hline chi2 & & $\mathrm{p}>$ chi2 & \\
\hline 0.274 & & 0.601 & \\
\hline \multicolumn{4}{|c|}{ Multicollinearity test } \\
\hline Variable & & VIF & $1 / \mathrm{VIF}$ \\
\hline Coca confiscation & & 2.04 & 0.49 \\
\hline ENACO & & 1.98 & 0.50 \\
\hline Crops & & 1.13 & 0.88 \\
\hline Mean & & 1.72 & \\
\hline
\end{tabular}

Table 6 shows the complimentary test to check the validity of the OLS regression. First, the autocorrelation test rejected the alternative hypothesis of autocorrelation. Moreover, the distribution test showed that the model had normal residual distribution. Furthermore, the homoscedasticity test portrays that there are no issues in data. Finally, the VIF analysis gives reassurance that data did not have multicollinearity issues.

Consequently, it is reasonable to declare that Lasso provided the correct set of variables to explain the dependent variable in the OLS regression. It is necessary, though, to analyze if those variables have any cause-effect relationship across time. 
Table 7

Lag selection test

\begin{tabular}{|c|c|c|c|c|c|c|c|c|}
\hline Lag & $\mathbf{L L}$ & LR & df & $\mathbf{p}$ & FPE & AIC & HQIC & SBIC \\
\hline 0 & -472.714 & & & & $4.40 \mathrm{E}+24$ & 68.102 & 68.0851 & $6.83 \mathrm{E}+01$ \\
\hline 1 & -445.006 & 55.415 & 16 & 0 & $9.50 \mathrm{E}+23$ & 66.4295 & 66.345 & 67.3424 \\
\hline 2 & -407.483 & 75.047 & 16 & 0 & $1.00 \mathrm{E}+23$ & 63.3547 & 63.2026 & 64.998 \\
\hline 3 & 413.086 & $1641.1^{*}$ & 16 & 0 & $1.5 \mathrm{e}-25^{*}$ & $-51.5836^{*}$ & $-51.8034^{*}$ & $-49.21 *$ \\
\hline
\end{tabular}

Table 7 shows the necessary step of choosing the lag number. The optimal number of lags was three, which was the number employed for the following tests.

Table 8

Stationary test

\begin{tabular}{|c|c|c|c|c|c|c|}
\hline & Variable & Test statistic & $1 \%$ c. value & $5 \%$ c. value & $10 \%$ c. value & $\mathbf{p}>\mathbf{Z}$ \\
\hline At level & \multirow{2}{*}{ Cocaine price } & -0.691 & -3.75 & -3 & -2.63 & 0.85 \\
\hline First difference & & -5.847 & -3.75 & -3 & -2.63 & 0 \\
\hline At level & \multirow{2}{*}{ ENACO acquisition } & 0.099 & -3.75 & -3 & -2.63 & 0.97 \\
\hline First difference & & -9.287 & -3.75 & -3 & -2.63 & 0 \\
\hline At level & \multirow{2}{*}{ Coca confiscation } & -2.533 & -3.75 & -3 & -2.63 & 0.11 \\
\hline First difference & & -8.421 & -3.75 & -3 & -2.63 & 0 \\
\hline At level & \multirow{2}{*}{ Crops } & -1.88 & -4.38 & -3.6 & -3.24 & 0.33 \\
\hline First difference & & -3.78 & -3.75 & -3 & -2.63 & 0 \\
\hline
\end{tabular}

Table 8 shows that all the studied variables had root issues at level but were stationary in the first difference.

Table 9

Johansen Test

\begin{tabular}{|c|c|c|c|c|c|}
\hline Maximum rank & Parameters & $\mathbf{L L}$ & Eigenvalue & Trace statistic & $5 \%$ critical value \\
\hline 0 & 36 & -418.93946 & . & 1396.5656 & 47.21 \\
\hline 1 & 43 & -171.48591 & 1 & 901.6585 & 29.68 \\
\hline 2 & 48 & 54.49126 & 1 & 449.7041 & 15.41 \\
\hline 3 & 51 & 277.63018 & 1 & $3.4263^{*}$ & 3.76 \\
\hline
\end{tabular}

Table 9 portrays that Var is the accurate since the trace statistic was lower than the critical value. Hence, it not possible to state that there were long-term relationships among the variables.

Table 10

VAR

\begin{tabular}{|c|c|c|c|c|c|c|c|}
\hline \multirow{2}{*}{ Cocaine price } & \multirow[t]{2}{*}{ Variable } & \multirow[t]{2}{*}{ Coefficient } & \multirow[t]{2}{*}{ Standard Error } & \multirow[t]{2}{*}{$\mathbf{z}$} & \multirow[t]{2}{*}{$\mathbf{P}>\mathbf{Z}$} & \multicolumn{2}{|c|}{$95 \%$ confidence interval } \\
\hline & & & & & & & \\
\hline & Cocaine price & 0.270 & 0.360 & 0.750 & 0.454 & -0.436 & 0.976 \\
\hline & ENACO & -0.474 & 0.153 & -3.110 & 0.002 & -0.774 & -0.175 \\
\hline & Confiscation & 0.005 & 0.014 & 0.320 & 0.748 & -0.023 & 0.032 \\
\hline & Crops & 0.001 & 0.009 & 0.140 & 0.889 & -0.016 & 0.018 \\
\hline & Constant & 1974.977 & 915.469 & 2.160 & 0.031 & 180.691 & 3769.263 \\
\hline \multicolumn{8}{|l|}{ ENACO } \\
\hline & Cocaine price & 0.226 & 0.383 & 0.590 & 0.554 & -0.523 & 0.976 \\
\hline & ENACO & 1.026 & 0.162 & 6.330 & 0.000 & 0.709 & 1.344 \\
\hline & Confiscation & -0.016 & 0.015 & -1.060 & 0.290 & -0.045 & 0.013 \\
\hline & Crops & 0.002 & 0.009 & 0.260 & 0.796 & -0.015 & 0.020 \\
\hline & Constant & -556.248 & 972.140 & -0.570 & 0.567 & -2461.607 & 1349.112 \\
\hline \multicolumn{8}{|l|}{ Cocaine price } \\
\hline & Cocaine price & 8.043 & 7.574 & 1.060 & 0.288 & -6.802 & 22.887 \\
\hline & ENACO & -1.241 & 3.211 & -0.390 & 0.699 & -7.534 & 5.052 \\
\hline & Confiscation & -0.074 & 0.296 & -0.250 & 0.803 & -0.654 & 0.506 \\
\hline & Crops & -0.193 & 0.180 & -1.080 & 0.282 & -0.545 & 0.159 \\
\hline & Constant & 20542.790 & 19248.690 & 1.070 & 0.286 & -17183.950 & 58269.540 \\
\hline \multicolumn{8}{|l|}{ Cocaine price } \\
\hline & Cocaine price & -15.555 & 10.624 & -1.460 & 0.143 & -36.378 & 5.267 \\
\hline & ENACO & 5.293 & 4.504 & 1.180 & 0.240 & -3.533 & 14.120 \\
\hline & Confiscation & 0.704 & 0.415 & 1.700 & 0.090 & -0.109 & 1.518 \\
\hline & Crops & -0.541 & 0.252 & -2.150 & 0.032 & -1.034 & -0.047 \\
\hline & Constant & 75978.970 & 26999.560 & 2.810 & 0.005 & 23060.800 & 128897.100 \\
\hline
\end{tabular}


In Table 10, the VAR results are depicted. Only ENACO seems to have a cointegration with the dependent variable. Among other variables, coca confiscation and crops had a cointegration with cocaine price. The relationships depicted in Table 10 are also known as short term relationships.

Table 11

Granger causality test

\begin{tabular}{|c|c|c|c|c|}
\hline Equation & Excluded & chi2 & df & prob $>$ chi2 \\
\hline \multirow[t]{4}{*}{ Cocaine price } & ENACO & 9.6452 & 1 & 0.002 \\
\hline & Confiscation & 0.10334 & 1 & 0.748 \\
\hline & Crops & 0.01931 & 1 & 0.889 \\
\hline & All & 11.193 & 3 & 0.011 \\
\hline \multirow[t]{4}{*}{ ENACO } & Cocaine price & 0.3506 & 1 & 0.554 \\
\hline & Confiscation & 1.1202 & 1 & 0.29 \\
\hline & Crops & 0.06666 & 1 & 0.796 \\
\hline & All & 1.3185 & 3 & 0.725 \\
\hline \multirow[t]{4}{*}{ Confiscation } & Cocaine price & 1.1276 & 1 & 0.288 \\
\hline & ENACO & 0.14937 & 1 & 0.699 \\
\hline & Crops & 1.1598 & 1 & 0.282 \\
\hline & All & 9.8251 & 3 & 0.02 \\
\hline \multirow[t]{4}{*}{ Crops } & Cocaine price & 2.1438 & 1 & 0.143 \\
\hline & ENACO & 1.3815 & 1 & 0.24 \\
\hline & Crops & 2.8794 & 1 & 0.09 \\
\hline & All & 9.6439 & 3 & 0.022 \\
\hline
\end{tabular}

In Table 11, the Granger test depicts that only ENACO had a relationship with the cocaine price in Peru. With the help of VAR and OLS, it is possible to state ENACO acquisition had a negative effect on the dependent variable. The independent variables had an influence on the cocaine price.

Table 12

Supplementary tests

\begin{tabular}{llll}
\hline Distribution test & & & \\
\hline Equation & chi2 & df & \\
\hline Cocaine price & 0.416 & 2 & $\mathrm{p}>$ chi2 \\
ENACO & 0.654 & 2 & 0.81217 \\
Confiscation & 1.287 & 2 & 0.72094 \\
Crops & 0.392 & 2 & 0.52542 \\
All & 2.75 & 8 & 0.82205 \\
\hline Autocorrelation test & & df & 0.94908 \\
Lag & chi2 & 16 & p chi2 \\
\hline 1 & 23.8266 & 16 & 0.09336 \\
2 & 23.7394 & 16 & 0.09535 \\
3 & 24.0189 & & 0.08909 \\
\hline
\end{tabular}

Table 12 portrays the assumption tests for the VAR analysis. First, the distribution test shows that all the variables had normal distributions. The autocorrelation test demonstrates that there was not any autocorrelation issue. Both tests provide evidence that the VAR and Granger analysis results are valid.

\section{Discussion}

The analysis studied the determinants of cocaine prices in Peru. Therefore, both national and international databases gave the initial set of variables. The Lasso technique selected the best variables. Also, both OLS and VAR tools helped to analyze the relationships between the variables. Finally, Granger analysis was fundamental for the cause-and-effect analysis. The main result is that the ENACO acquisition had an adverse association with cocaine prices. Therefore, it is possible to state that ENACO helped to lower cocaine prices in the Peruvian market. Thus, money transfers to farmers can change cocaine prices, as studied by Thompson and Uggen (2012).

Farmers who sell their crops to ENACO are out of the illegal market and avoid judicial issues. Hence, as Félix \& Portugal (2017) found, a more comprehensive coca understanding might lower the cocaine price. Thus, making it less attractive for illegal farmers. However, cheap cocaine might have undesirable effects, as noted by Sumnall et al. (2004). The reason is that lowering the cocaine price might encourage users to buy more. Also, it is possible to state that ENACO acquisitions have a certain quality of coca leaves. Therefore, it could affect the quality of cocaine. Freeborn (2003) found that buyers do not prefer low cocaine quality. The OLS analysis unearthed that coca confiscation had a positive effect on cocaine prices, which does not agree with the findings of DiNardo (1993). Scarcity might clarify the findings difference. Then, seizures cause fewer coca leaves available for cocaine production. When the demand rises but the offer does not, it makes the prices higher. Similarly, Desimone \& Farrelly (2001) found that coca seizures had an impact on drug prices. 


\section{Conclusion}

The current analysis found that ENACO acquisition, coca leaf confiscation, and crops affected the cocaine prices in Peru. VAR and Granger analysis found that the ENACO acquisition had a negative short-term impact on cocaine prices. Thus, it is possible to say that ENACO policies did influence cocaine prices. Since ENACO is a means for farmers to stay out of problems, higher purchases seem to lower the cocaine prices. The reason could be the acquisition price. If prices were attractive enough, more farmers would sell their production to ENACO rather than to Narcos. However, coca leaf seizures do not have a similar effect on price. Scarcity might play a role there since illegal products are more valuable. Nonetheless, low cocaine prices invite users to buy it. Analogously, if the prices were high, users would replace cocaine with cheaper drugs. Hence, the problem with drug consumption might not be the price itself. Instead, they are the inner impulses of users that push them to consume and harm their lives. In consequence, the government should focus on education programs to convince people to stay out of drugs. Many times, society believes that drug users are people with low socioeconomic status. However, if that were certain, no one would pay for cocaine. Consequently, tackling the motivations of drug users despite their situation is a means to eradicate cocaine and other drugs from the streets.

\section{Conflict of interest}

The authors state that they do not have any conflicts of interest.

\section{References}

Arif, A., \& World Health Organization. (1987). Adverse health consequences of cocaine abuse. World Health Organization.

Benvenuto, F., Piana, M., Campi, C., \& Massone, A. M. (2018). A hybrid supervised/unsupervised machine learning approach to solar flare prediction. The Astrophysical Journal, 853(1), 90

Biondich, A. S., \& Joslin, J. D. (2016). Coca: the history and medical significance of an ancient Andean tradition. Emergency medicine international, 2016.

Burton, A. L. (2021). OLS (Linear) Regression. The Encyclopedia of Research Methods in Criminology and Criminal Justice, 2, 509-514.

Castillo Gallado, M. (2012). La economía de la coca: La dimensión silenciada de la dependencia. Ana Gabriela Contreras García. Las Relaciones Internacionales de la Pobreza en América Latina y el Caribe. Buenos Aires. CLACSO.

Conzelman, C. S., \& White, D. M. (2016). The botanical science and cultural value of Coca leaf in South America. Roadmaps to regulation: coca, cocaine, and derivatives. Oxford: The Beckley Foundation.

Daley, D. C. (2013). Family and social aspects of substance use disorders and treatment. Journal of food and drug analysis, 21(4), S73-S76.

Daniels, A. (2006). EE UU y la guerra contra las drogas en Latinoamérica. Política Exterior, 131-140.

DeSimone, J., \& Farrelly, M. C. (2003). Price and enforcement effects on cocaine and marijuana demand. Economic Inquiry, 41(1), 98-115.

DEVIDA (2020). Informe sobre la demanda de hoja de coca para fines tradicionales e industriales. Lima, Comisión Nacional para el Desarrollo y Vida sin Drogas - DEVIDA

DEVIDA. (2017). Estrategia Nacional de Lucha Contra las Drogas 2017-2021.

Díaz, A., Olivera, H., Lima, E., Nappo, S. A., \& Olatawura, M. O. (1995). WHO/UNICRI Cocaine Project. The Natural History of Cocaine Abuse: A case study endeavor: WHO/UNICRI Cocaine Project.

DiNardo, J. (1993). Law enforcement, the price of cocaine and cocaine use. Mathematical and computer Modelling, 17(2), 53-64.

dos Reis Jr, A. (2009). Sigmund Freud (1856-1939) and Karl Köller (1857-1944) and the discovery of local anesthesia. Brazilian Journal of Anesthesiology, 59(2), 244-257.

Durand, F. (2005). El problema cocalero y el comercio informal para uso tradicional. Debate Agrario, 39, $109-125$.

Esquivel, F. A., García Sandoval, J. R., \& Aldape Ballesteros, L. A. (2019). Técnicas de comercialización y diversificación de cultivos para exportación en el sector agroalimentario en México. Revista Venezolana de Gerencia, 24(88).

Félix, S., \& Portugal, P. (2017). Drug decriminalization and the price of illicit drugs. International Journal of Drug Policy, 39 , 121-129.

Fernández López, J. A. (2017). The Norm Prohibiting the Chewing of Coca Leaf: From the International System to the Colombian State. Universidad del Rosario.

Fonti, V., \& Belitser, E. (2017). Feature selection using lasso. VU Amsterdam Research Paper in Business Analytics, 30, 125.

Freeborn, B. A. (2006). An equilibrium search model of the retail cocaine market and drug law enforcement. University of Virginia.

Fryer Jr, R. G., Heaton, P. S., Levitt, S. D., \& Murphy, K. M. (2013). Measuring crack cocaine and its impact. Economic Inquiry, 51(3), 1651-1681.

Glave, M., \& Rosemberg, C. (2005). La Comercialización De Hoja De Coca En El Perú: Análisis Del Mercado Formal. Perú Grade. 
Gootenberg, P. (2001). Between Coca and Cocaine: A Century or More of US-Peruvian Drug Paradoxes, 1860-1980 (No. 251). Latin American Program, Woodrow Wilson International Center for Scholars.

Grinspoon, L., \& Bakalar, J. B. (1981). Coca and cocaine as medicines: an historical review. Journal of ethnopharmacology, 3(2-3), 149-159.

Hossain, A., Kamruzzaman, M., \& Ali, M. A. (2015). Vector Autoregressive (VAR) Modeling and Projection of DSE. Chinese Business Review, 14(6), 273-289.

Lütkepohl, H. (2003). Vector Autoregressions. In A Companion to Theoretical Econometrics, B.H. Baltagi (Ed.). 678-699.

McDermott, J., Bargent, J., den Held, D., \& Fernanda Ramírez, M. (2021). The Cocaine Pipeline to Europe. Global Initiative Against Transnational Organized Crime and Insight Crime.

National Institute on Drug Abuse. (2016). Cocaine Research Report. May 1-29.

Uteulievna, N. S., Evgenievich, G. I., \& Konstantinovna, B. T. (2016). The influence of macroeconomic factors to the dynamics of stock exchange in the Republic of Kazakhstan. Экономика региона, 12(4).

Pacini, D., \& Franquemont, C. (1986). Coca and cocaine. Cambridge: Cultural Survival.

Papanicolas, I., \& McGuire, A. (2011). Using a Vector Autoregression Framework to measure the quality of English NHS hospitals.

Piazza, N. J., \& Yeager, R. D. (1989). Cocaine.

Reitermanová, Z. (2010). WDS'10 Proceedings of Contributed Papers.

Rojas, L., \& Parra, D. (2016). Procesos de sustitución y erradicación de cultivos ilícitos a nivel mundial: un punto de partida para Colombia.

Seelig, M. G. (1941). History of cocaine as a local anesthetic. Journal of the American Medical Association, 117(15), 12841284.

Spillane, J. F. (1996). Modern drug, modern menace: The legal use and distribution of cocaine in the United States, 18801920.

StataCorp, L. L. C. (2017). STATA finite mixture models reference manual. StataCorp LLC: College Station, TX, USA.

Stock, J. H., \& Watson, M. W. (2001). Vector autoregressions. Journal of Economic perspectives, 15(4), 101-115.

Sumnall, H. R., Tyler, E., Wagstaff, G. F., \& Cole, J. C. (2004). A behavioural economic analysis of alcohol, amphetamine, cocaine and ecstasy purchases by polysubstance misusers. Drug and alcohol dependence, 76(1), 93-99.

Thompson, M., \& Uggen, C. (2012). Dealers, thieves, and the common determinants of drug and nondrug illegal earnings. Criminology, 50(4), 1057-1087.

Thoumi, F. E. (2005). A modest proposal to clarify the status of coca in the United Nations conventions. Crime, law, and social change, 42(4), 297-307.

Tibshirani, R. (1996). Regression shrinkage and selection via the lasso. Journal of the Royal Statistical Society: Series B (Methodological), 58(1), 267-288.

Wesson, D. R., \& Smith, D. E. (1977). Chapter VII Cocaine: its use for central nervous system stimulation including recreational and medical uses. Cocaine: 1977, 137.

Wooldridge, J. M. (2010). Econometric analysis of cross section and panel data. MIT press.

Yang, K., Tu, J., \& Chen, T. (2019). Homoscedasticity: An overlooked critical assumption for linear regression. General psychiatry, 32(5).

Trigoso, N. Z. (2017). Dinámicas locales en torno al cultivo de hoja de coca: elementos para el estudio desde el mercado ilegal de la cocaína. Revista de Ciencia Política y Gobierno, 4(7), 9-29.

Zhu, H., Wilson, F. A., Stimpson, J. P., \& Pagán, J. A. (2014). Correlation between cocaine prices and purity with trends in emergency department visits in a major metropolitan area. Journal of Urban Health, 91(5), 1009-1018. 
C 2022 by the authors; licensee Growing Science, Canada. This is an open access article distributed under the terms and conditions of the Creative Commons Attribution (CC-BY) license (http://creativecommons.org/licenses/by/4.0/). 